\title{
Litogeoquímica e quimioestratigrafia dos basaltos da Província Magmática do Paraná, no município de Araçatuba (SP)
}

\author{
Marli Torres ${ }^{1}$, Marcos Aurélio Farias de Oliveira ${ }^{2}$, Antonio José Ranalli Nardy ${ }^{2}$ \\ \& Fábio Braz Machado ${ }^{3}$
}

\begin{abstract}
Resumo A Formação Serra Geral no Município de Araçatuba, região noroeste do Estado de São Paulo aflora principalmente no vale do Rio Tietê e de seus afluentes. Com a perfuração de um poço para a captação de água de subsuperfície, foi possível observar e amostrar uma seqüência de 980 metros constituída por 27 derrames, com espessuras individuais variando entre 10 e 84 metros. Foram também coletadas nove amostras de superfície oriundas de três pedreiras desativadas e do leito do Ribeirão Baguaçu. Os dados geoquímicos dessas amostras revelaram tratar-se de basaltos toleíticos do tipo alto-Ti, com concentrações em $\mathrm{TiO}_{2}$ variando entre $1,77 \%$ e 3,66\%, podendo ser divididos em dois subtipos distintos, denominados de Pitanga e Paranapanema. O primeiro está enriquecido em $\mathrm{Nb}(8 \%), \mathrm{K}(9 \%), \mathrm{La}(11 \%), \mathrm{Ce}(18 \%), \mathrm{P}(8 \%), \mathrm{Nd}(20 \%), \mathrm{Zr}$ (19\%), Sm (17\%), $\mathrm{Eu}(15 \%)$ e Ti $(15 \%)$ em relação ao segundo. No furo de sondagem os basaltos dos tipos Pitanga e Paranapanema se alternam, sendo que os primeiros estão em contato com os arenitos eólicos da Formação Botucatu, a uma profundidade de 980 metros, seguindo até 748 metros, em uma sucessão de cinco derrames. A partir de então, inicia-se uma nova seqüência de 10 derrames de basaltos do tipo Paranapanema, até uma profundidade de 396 metros, seguida de três derrames de basaltos do tipo Pitanga, até 268 metros. Daí até a superfície é observada uma pilha de 9 derrames de basaltos do tipo Paranapanema, que é sobreposta pelos derrames observados em superfície, todos do tipo Paranapanema. Assim, a quimioestratigrafia estabelecida para a região parece indicar que essa seqüência de rochas vulcânicas pode ter sido abastecida por mais de uma câmara magmática, que extravasaram suas lavas em épocas distintas, iniciando com basaltos do tipo Pitanga, em contato com os arenitos da Formação Botucatu, e encerrando a pilha edificada com aqueles do tipo Paranapanema.
\end{abstract}

Palavras-chave: Formação Serra Geral, vulcanismo mesozóico, quimioestratigrafia.

\begin{abstract}
Lithogeochemistry and chemostratigraphy of basalts from Paraná Magmatic Province in the Araçatuba region, State of São Paulo. The Serra Geral Formation in the Araçatuba region, northwest of São Paulo State, Brazil, crops chiefly in the Tietê river valley and it's affluent. In a drilling of a well to get water in the subsurface it was possible to observe and sample a sequence of $980 \mathrm{~m}$ represented by 27 lava flows, which individual thickness vary from 10 to $84 \mathrm{~m}$. Besides it 9 samples were collected in the surface from 3 deactivated quarries and in the Baguaçu river bed. Some of these rocks were analyzed and geochemical data show that they represent tholeiitic basalt of high-Ti type with $\mathrm{TiO}_{2}$ concentration between $1,77 \%$ and $3,66 \%$ and that may be divided into two distinct sub types, named Pitanga and Paranapanema. The first type is enriched in $\mathrm{Nb}(8 \%), \mathrm{K}(9 \%)$, La (11\%), Ce (18\%), P (8\%), Nd (20\%), Zr (19\%), Sm (17\%), Eu (15\%) and Ti $(15 \%)$ in relation to the second. In the samples of the drill hole basalt of the Pitanga and Paranapanema types alternate themselves and the first group is in contact with the sandstones of the Botucatu Formation in a depth of $980 \mathrm{~m}$ following until $748 \mathrm{~m}$ in a succession of 5 lava flows. Since then begin a new sequence of 10 flows of Paranapanema type until the deep of $396 \mathrm{~m}$ followed by three lava flows of Pitanga type basalt until $268 \mathrm{~m}$. From the last point until the surface a sequence of 9 flows of the Paranapanema type is observed.
\end{abstract}

Keywords: Serra Geral Formation, mesozoic volcanism, chemostratigraphy.

INTRODUÇÃO A Província Magmática do Paraná é constituída predominantemente pelos derrames eocretácicos da Formação Serra Geral, que cobrem cerca de $75 \%$ da superfície da Bacia do Paraná, sendo caracterizados predominantemente por basaltos de natureza toleítica, que segundo Bellieni et al. (1983, 1984a, b), podem ser divididos em dois grandes grupos: alto-Ti $\left(\mathrm{TiO}_{2} \geq .2 \%\right)$ e baixo-Ti $\left(\mathrm{TiO}_{2}<2 \%\right)$. Os do primeiro grupo estão concentrados preferencialmente na porção norte da bacia, ou seja, ao norte do paralelo $24^{\circ}$,

1 - Programa de Pós-Graduação em Geologia Regional, Instituto de Geociências e Ciências Exatas, UNESP, Rio Claro (SP), Brasil.

E-mail: mar.torres@terra.com.br

2 - Instituto de Geociências e Ciências Exatas, UNESP, Rio Claro (SP), Brasil. E-mail: maurelio@rc.unesp.br, nardy@rc.unesp.br

3 - Programa de Pós-Graduação em Geologia Regional, Instituto de Geociências e Ciências Exatas, UNESP, Rio Claro (SP) e UNISAL,

Centro Universitário Salesiano de São Paulo, Americana (SP), Brasil. E-mail: fabiobm@rc.unesp.br 
enquanto que os do segundo na porção sul. Estudos posteriores revelaram que estes dois grupos podem ser subdivididos em vários outros conforme mostram os dados de Mantovani et al. (1985), Marques et al. (1989). Peate et al. (1992), baseado nas concentrações de $\mathrm{TiO}_{2}$ e outros elementos-traço, subdividiram o grupo alto-Ti em 3 subgrupos distintos denominados Urubici $\left(\mathrm{TiO}_{2}>3,3 \%, \mathrm{Sr}>550 \mathrm{ppm}\right.$; $\mathrm{Ti} / \mathrm{Y}>500$ e $\left.\mathrm{Zr} / \mathrm{Y}>6,5\right)$, Pitanga $\left(\mathrm{TiO}_{2}>2,9 \%, \mathrm{Sr}>350 \mathrm{ppm}\right.$; Ti/Y $>350$ e $\mathrm{Zr} / \mathrm{Y}$ $>5,5)$ e Paranapanema $\left(1,7 \%<\mathrm{TiO}_{2}<3,2 \%, 200 \mathrm{ppm}<\right.$ $\mathrm{Sr}<450 \mathrm{ppm}$; Ti $/ \mathrm{Y}>330$ e $4<\mathrm{Zr} / \mathrm{Y}<7$ ). O grupo baixo-Ti, foi subdividido em 3 outros subgrupos denominados: Gramado $\left(0,75 \%<\mathrm{TiO}_{2}<1,9 \%, 140 \mathrm{ppm}<\mathrm{Sr}\right.$ $<400 \mathrm{ppm}$; Ti $/ \mathrm{Y}<300$ e 3,5 $<\mathrm{Zr} / \mathrm{Y}<6,5)$, Esmeralda $\left(1,1 \%<\mathrm{TiO}_{2}<2,3 \%, 120 \mathrm{ppm}<\mathrm{Sr}<250 \mathrm{ppm} ; \mathrm{Ti} / \mathrm{Y}<330\right.$ e $2<\mathrm{Zr} / \mathrm{Y}<5)$ e Ribeira $\left(1,5 \%<\mathrm{TiO}_{2}<2,3 \%, 200 \mathrm{ppm}<\right.$ $\mathrm{Sr}<375 \mathrm{ppm} ; \mathrm{Ti} / \mathrm{Y}>300$ e 3,5< $\mathrm{Zr} / \mathrm{Y}<7)$. Posteriormente, Peate (1997), Ernesto et al. (1999) e Marques et al. (1999), demonstraram que esses subgrupos de basaltos apresentam assinaturas isotópicas diferentes, e podem ser considerados magmas-tipo distintos bem como, terem sido gerados a partir de fontes mantélicas diferentes.

O presente trabalho foi desenvolvido na porção norte da Bacia do Paraná, no Município de Araçatuba, a noroeste do Estado de São Paulo, onde ocorrem basaltos da Formação Serra Geral e rochas sedimentares do Grupo Bauru. Dados petrográficos e geoquímicos de basaltos obtidos de amostras coletadas em afloramentos de antigas pedreiras, ao longo do Rio Baguaçu e de um poço tubular profundo para a captação de água subterrânea tiveram como objetivo, identificar os derrames que edificaram a seqüência vulcânica observada e sua tipologia magmática. Tendo em vista a dificuldade de se poder estudar uma espessa seqüência de rochas vulcânicas da Formação Serra Geral em uma pilha vertical, onde os diferentes derrames estão dispostos segundo sua posição estratigráfica original, desde o contato inferior com os arenitos eólicos da Formação Botucatu até a superfície, acredita-se que os resultados ora obtidos possam somar-se àqueles existentes na literatura $\mathrm{e}$ contribuir para um melhor entendimento da quimioestratigrafia da Província Magmática do Paraná.

\section{LOCALIZAÇÃO E ASPECTOS GEOLÓGICOS} DA ÁREA ESTUDADA A região estudada está situada na porção sudeste do município de Araçatuba, figura 1 , compreendendo uma área de 68,64 ha e foi mapeada na escala de 1:50.000 através de trabalhos de campo auxiliados pela análise de fotografias áreas (escala de 1:2000), empregando-se como base cartográfica a folha topográfica de Araçatuba do IGG (1967), na escala de 1:50.000. Além dos trabalhos de campo, foram realizados o acompanhamento e amostragem de um poço tubular profundo, perfurado pela Prefeitura Municipal de Araçatuba, que atravessou todo o pacote de natureza vulcânica da Formação Serra Geral e atingiu os arenitos eólicos da Formação Botucatu, cuja localização está representada no mapa da figura 1 .

A geologia da região de Araçatuba é caracteri- zada predominantemente pelas rochas de natureza sedimentar, silicicláticas do Grupo Bauru e pelos derrames de basaltos da Formação Serra Geral.

Duas unidades do Grupo Bauru são observadas na região de estudo. A inferior, denominada de Araçatuba, é constituída por arenitos marrom-avermelhados, finos a médios, de caráter subarcosiano, e localmente, com a presença de cimento e nódulos carbonáticos. As estruturas sedimentares observadas são pouco pronunciadas, predominando os bancos arenosos maciços com espessuras métricas e decimétricas, e seu contato basal com a Formação Serra Geral é descontínuo e abrupto. $\mathrm{Na}$ região estudada, a Formação Araçatuba aflora de maneira restrita, quase que exclusivamente às margens do Rio Tietê, tendo sido praticamente submersa pelas águas da Hidrovia Tietê-Paraná.

A Formação Adamantina é a unidade estratigráfica predominante e é caracterizada pela presença de arenitos finos a médios, de coloração avermelhada, onde se observa a presença de estratificação cruzada de pequeno à médio porte e por lamitos cinza-esverdeados. Os litotipos lamíticos afloram nas margens do Córrego Machadinho, assentando-se diretamente sobre os basaltos da Formação Serra Geral. Sobrepõe-se à Formação Araçatuba, sendo que a passagem para a unidade inferior é transicional e interdigitada.

A Formação Serra Geral é constituída exclusivamente por basaltos cinza escuros a negros variando para tonalidades vermelho-arroxeadas, dispostos em derrames subhorizontais, via de regra afaníticos, maciços gradando para tipos vesiculares ou amigdaloidais em direção ao topo e a base dos derrames. A ocorrência dessas rochas está restrita aos vales dos grandes rios, como é o caso do Tietê e de seus principais afluentes, de onde se destaca o Ribeirão Baguaçu. Parte dos afloramentos existentes está hoje submersa no Lago Três Irmãos. Também foram encontradas ocorrências de basaltos em três pedreiras da antiga Rede Ferroviária Federal (RFFSA), atualmente desativadas e localizadas no Parque Ecológico do Baguaçu, na Avenida dos Araçás e na Avenida dos Estados, figura 1.

O poço tubular (PMA) perfurado pela Prefeitura Municipal de Araçatuba, está localizado a SE da cidade $\left(21^{\circ} 13\right.$ ' 23,4 ' 'de latitude sul e $50^{\circ} 25^{\prime} 2,57^{\prime}$ 'de longitude oeste, e a 348 metros de altitude), figura 1, foi uma fonte importante de informações de subsuperfície na região estudada, tendo sido perfurado, até uma profundidade de 1008 metros, com uma espessura de 980 metros para a pilha de derrames da Formação Serra Geral. Nos últimos 24 metros, ou seja entre 956 e 980 metros de profundidade, foi observada a presença de intercalações de arenitos da Formação Botucatu, cujo topo foi atingido em 980 metros de profundidade. A perfuração prosseguiu por mais 28 metros abaixo, conforme mostra a seção colunar da figura 2.

AMOSTRAGEM A amostragem de superfície se concentrou no leito do Ribeirão Baguaçu-Cachoeirinha, no Parque Ecológico Baguaçu e nas cavas de três antigas pedreiras desativadas, totalizando 8 amostras, 


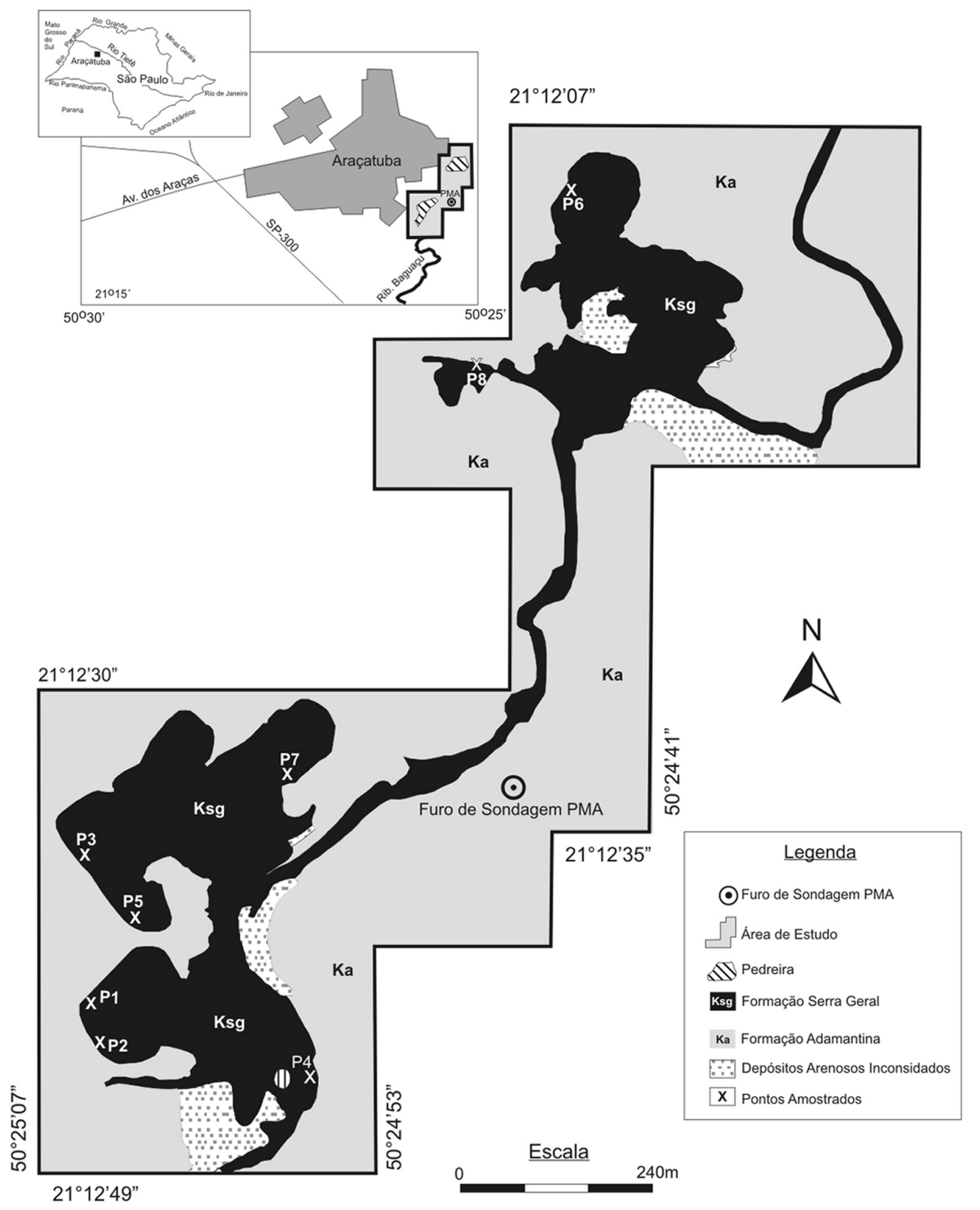

Figura 1 - Mapa geológico e de localização da região de Araçatuba (no destaque da figura) onde estão assinalados os locais de amostragem e furo de sondagem (PMA).

localizadas no mapa da figura 1 .

A perfuração do poço profundo foi executada pelo método rotativo, com circulação direta e recuperação de amostras de calha realizada ao longo de toda a sucessão de derrames da Formação Serra Geral, adotando-se como critério, a coleta de amostras a cada 2 metros perfurados, o que resultou um conjunto de 490 amostras, figura 3. Desse total, após inspeção visual, foram selecionadas 40 amostras para análises petrográficas e dessas, retiradas aquelas que se apresentavam alteradas ou com presença de amígdalas, sendo assim, escolhidas 23 amostras para análises químicas de elementos maiores, menores e traços (Tab. 1).
PETROGRAFIA As amostras de superfície coletadas foram laminadas e estudadas por meio de microscopia de luz polarizada. As amostras de calha selecionadas, compostas por fragmentos de rocha, representativas dos intervalos perfurados, foram imersas em resina do tipo Epóxi para a montagem e confecção das lâminas petrográficas. Depois de seca a resina, as amostras foram cortadas e devidamente desgastadas para a confecção das seções delgadas, figura 4.

Os basaltos estudados são caracterizados pela presença de cinco fases minerais essenciais: clinopiroxênio cálcico (augita) e subcálcico (pigeonita), plagioclá- 


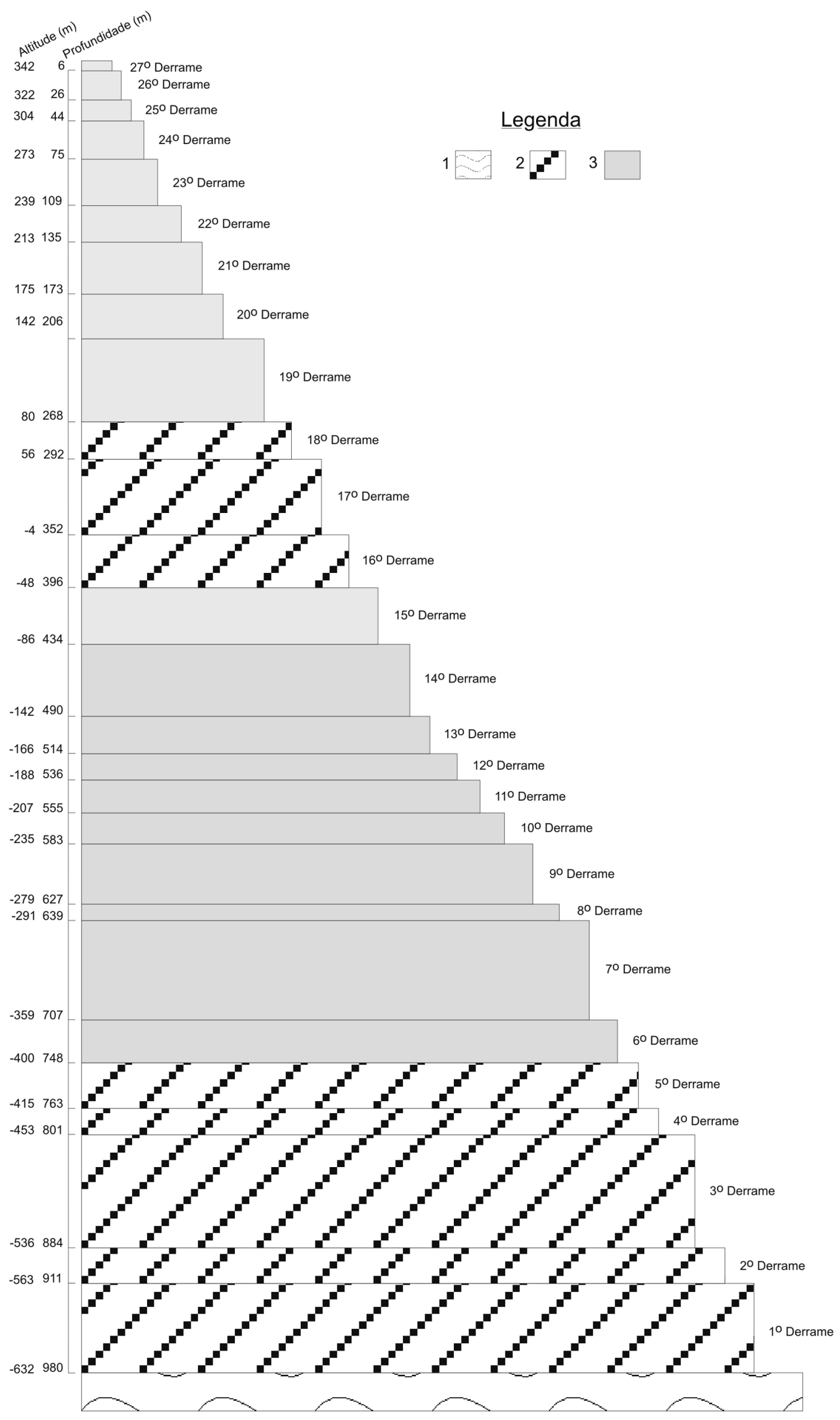

Figura 2 - Seção colunar do furo de sondagem, mostrando a seqüência de derrames individualizados e seus respectivos magmas-tipo. Legenda: 1- Arenitos da Formação Botucatu. Basaltos da Formação Serra Gera dos tipos 2- Pitanga e 3- Paranapanema. 
Tabela 1 - Dados químicos dos basaltos de Araçatuba (SP). Os elementos maiores e menores estão apresentados na forma de percentagem em peso. $P=$ amostras de superficie, $P M A=$ amostras provenientes do furo de sondagem. Siglas da mineralogia normativa CIPW: $Q z=$ quartzo, Or= ortoclásio, Ab=albita, An= anortita, $H y=$ hiperstênio, Di= diopsídio, $M t=$ magnetita, $I l=i l m e n i t a, H m=$ hematita e Ap= apatita.

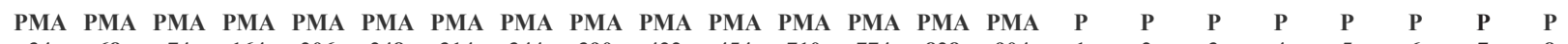

$\begin{array}{llllllllllllllllllllllllllll}34 & 68 & 74 & 164 & 206 & 248 & 314 & 344 & 390 & 422 & 454 & 710 & 774 & 828 & 904 & 1 & 2 & 3 & 4 & 5 & 6 & 7 & 8\end{array}$

\begin{tabular}{lllllllllllllllllllllllllll}
\hline $\mathrm{SiO}_{2}$ & 50,30 & 52,01 & 52,05 & 50,85 & 48,83 & 50,72 & 50,10 & 51,08 & 50,37 & 50,44 & 49,76 & 54,38 & 50,01 & 51,49 & 50,07 & 50,35 & 51,35 & 51,23 & 50,19 & 50,40 & 52,01 & 50,07 & 50,45
\end{tabular} $\begin{array}{llllllllllllllllllllllllll}\mathrm{TiO}_{2} & 2,03 & 2,06 & 1,77 & 1,88 & 1,95 & 1,95 & 3,56 & 3,14 & 3,01 & 3,23 & 2,57 & 2,81 & 3,66 & 3,74 & 3,12 & 2,41 & 2,35 & 2,36 & 2,69 & 2,51 & 2,33 & 2,43 & 2,32\end{array}$ $\begin{array}{lllllllllllllllllllllllllllllll}\mathrm{Al}_{2} \mathrm{O}_{3} & 12,91 & 12,68 & 12,95 & 13,26 & 12,73 & 13,25 & 12,72 & 13,09 & 12,89 & 12,46 & 13,40 & 12,93 & 12,68 & 12,22 & 12,55 & 13,16 & 12,94 & 13,06 & 13,18 & 13,45 & 12,84 & 13,02 & 13,23\end{array}$ $\begin{array}{llllllllllllllllllllllllll}\mathrm{Fe}_{2} \mathrm{O}_{3}{ }^{*} & 10,74 & 5,19 & 7,42 & 4,26 & 9,72 & 7,06 & 6,91 & 5,91 & 5,51 & 9,06 & 9,38 & 9,47 & 7,13 & 6,49 & 8,50 & 10,30 & 6,20 & 6,66 & 9,15 & 7,44 & 8,70 & 8,75 & 7,62\end{array}$ $\begin{array}{lllllllllllllllllllllllllllllll}\mathrm{FeO} & 4,24 & 9,03 & 6,43 & 9,27 & 4,74 & 7,70 & 8,12 & 8,29 & 8,52 & 5,81 & 5,24 & 3,46 & 7,34 & 7,65 & 5,80 & 4,02 & 7,46 & 7,31 & 6,90 & 5,93 & 5,22 & 5,50 & 6,71\end{array}$ $\begin{array}{lllllllllllllllllllllllllll}\mathrm{MnO} & 0,22 & 0,21 & 0,22 & 0,21 & 0,21 & 0,20 & 0,23 & 0,20 & 0,21 & 0,21 & 0,20 & 0,19 & 0,21 & 0,23 & 0,21 & 0,21 & 0,19 & 0,20 & 0,26 & 0,20 & 0,21 & 0,21 & 0,21\end{array}$ $\begin{array}{llllllllllllllllllllllllll}\mathrm{MgO} & 4,96 & 5,01 & 5,11 & 5,73 & 5,14 & 5,41 & 4,45 & 4,94 & 5,00 & 4,66 & 5,17 & 3,81 & 4,51 & 4,26 & 4,63 & 5,26 & 5,08 & 5,17 & 3,27 & 5,70 & 5,02 & 5,76 & 5,01\end{array}$ $\begin{array}{lllllllllllllllllllllllllllll}\mathrm{CaO} & 9,30 & 8,91 & 9,09 & 9,75 & 8,88 & 9,19 & 8,48 & 8,30 & 8,79 & 8,45 & 9,52 & 7,33 & 8,55 & 7,81 & 8,40 & 8,80 & 8,76 & 8,74 & 7,32 & 8,94 & 8,22 & 8,58 & 8,51\end{array}$ $\begin{array}{llllllllllllllllllllllllllll}\mathrm{Na}_{2} \mathrm{O} & 2,90 & 2,41 & 2,51 & 2,35 & 3,54 & 2,38 & 2,66 & 2,69 & 2,58 & 2,80 & 2,61 & 3,38 & 2,65 & 2,54 & 2,61 & 2,63 & 2,58 & 2,44 & 3,09 & 2,34 & 2,33 & 2,16 & 2,41\end{array}$ $\begin{array}{llllllllllllllllllllllllll}\mathrm{K}_{2} \mathrm{O} & 0,60 & 0,99 & 1,05 & 0,67 & 1,25 & 1,01 & 1,18 & 0,87 & 1,26 & 0,78 & 0,51 & 1,46 & 0,95 & 1,60 & 1,15 & 1,45 & 1,40 & 1,37 & 1,49 & 1,27 & 1,45 & 1,38 & 2,07\end{array}$

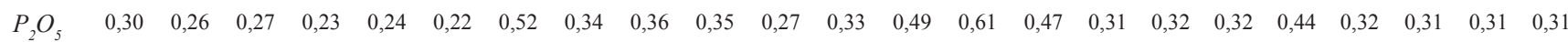

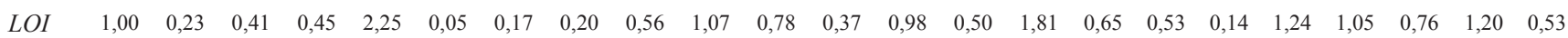
$\begin{array}{lllllllllllllllllllllllll}\text { SOMA } & 99,51 & 98,99 & 99,27 & 98,20 & 99,47 & 99,14 & 99,09 & 99,07 & 99,06 & 99,33 & 99,40 & 99,92 & 99,17 & 99,13 & 99,33 & 99,55 & 99,17 & 99,01 & 99,22 & 99,55 & 99,40 & 99,37 & 99,38\end{array}$

Norma CIPW (\% peso)

\begin{tabular}{|c|c|c|c|c|c|c|c|c|c|c|c|c|c|c|c|c|c|c|c|c|c|c|c|}
\hline \multicolumn{24}{|c|}{ Norma CIPW (\% peso) } \\
\hline$Q z$ & 9,78 & 9,18 & 10,77 & 6,32 & 3,34 & 8,41 & 9,62 & 9,59 & 7,28 & 11,53 & 10,08 & 12,65 & 10,90 & 12,00 & 11,1 & 8,39 & 8,25 & 9,00 & 10,36 & 9,30 & 12,67 & 9,29 & 7,34 \\
\hline Or & 3,57 & 5,84 & 6,18 & 3,94 & 7,39 & 5,97 & 6,96 & 5,13 & 7,46 & 4,62 & 2,99 & 8,65 & 5,62 & 9,47 & 6,79 & 8,57 & 8,29 & 8,07 & 8,81 & 7,48 & 8,56 & 8,17 & 12,23 \\
\hline$A$ & 24,54 & 20,43 & 21,24 & 19,98 & 29,94 & 20,13 & 22,47 & 22,8 & 21,79 & 23,69 & 22,08 & 28,58 & 22,45 & 21,47 & 22,10 & 22,28 & 21,80 & 20,67 & 26,16 & 19,76 & 19,73 & 18,31 & 20,37 \\
\hline$A n$ & 20,42 & 20,85 & 20,97 & 23,67 & 15,15 & 22,50 & 19,30 & 21,04 & 19,87 & 19,14 & 23,37 & 15,80 & 19,89 & 17,22 & 19,12 & 19,82 & 19,60 & 20,64 & 17,70 & 22,47 & 20,29 & 21,73 & 19,18 \\
\hline Hy & 3,79 & 12,28 & 6,90 & 14,94 & 2,94 & 9,91 & 6,75 & 10,14 & 9,84 & 4,21 & 4,90 & 2,83 & 5,34 & 6,23 & 4,50 & 5,22 & 8,65 & 8,73 & 2,89 & 7,41 & 5,85 & 9,3 & 6,63 \\
\hline$D i$ & 18,47 & 17,70 & 17,74 & 18,98 & 21,28 & 17,34 & 15,42 & 14,41 & 17,29 & 15,95 & 17,19 & 14,34 & 15,19 & 13,95 & 15,19 & 16,96 & 17,48 & 16,52 & 12,33 & 15,49 & 14,35 & 14,81 & 16,61 \\
\hline$M t$ & 8,52 & 8,97 & 11,79 & 7,66 & 10,30 & 11,47 & 11,32 & 9,90 & 9,37 & 10,05 & 10,10 & 3,62 & 11,53 & 10,63 & 10,31 & 6,64 & 10,19 & 10,83 & 14,38 & 11,74 & 10,75 & 7,97 & 12,12 \\
\hline$I l$ & 3,85 & 3,91 & 3,36 & 3,57 & 3,71 & 3,70 & 6,76 & 5,97 & 5,71 & 6,13 & 4,88 & 5,34 & 6,96 & 7,10 & 5,93 & 4,58 & 4,46 & 4,49 & 5,11 & 4,77 & 4,43 & 4,62 & 4,40 \\
\hline $\mathrm{He}$ & 5,33 & - & - & - & 3,14 & - & - & - & - & & 3,00 & 7,35 & - & - & 2,03 & 6,16 & - & - & - & - & 1,87 & - & - \\
\hline$A p$ & 0,72 & 0,61 & 0,65 & 0,54 & 0,56 & 0,53 & 1,24 & 0,81 & 0,85 & 0,83 & 0,63 & 0,78 & 1,17 & 1,44 & 1,11 & 0,75 & 0,75 & 0,75 & 1,04 & 0,75 & 0,74 & 0,74 & 0,74 \\
\hline
\end{tabular}

Elementos-traço (ppm)

\begin{tabular}{lcccccccccccccccccccccccccc}
\hline $\mathrm{Cr}$ & 122 & 141 & 148 & 171 & 130 & 151 & 99 & 102 & 168 & 129 & 132 & 129 & 92 & 102 & 115 & 161 & 163 & 140 & 127 & 128 & 136 & 121 & 128 \\
$\mathrm{Ni}$ & 46 & 46 & 49 & 58 & 47 & 46 & 31 & 55 & 54 & 39 & 45 & 39 & 61 & 40 & 34 & 53 & 55 & 51 & 48 & 50 & 50 & 57 & 51 \\
$\mathrm{Rb}$ & 8 & 18 & 6 & 2 & 15 & 8 & 5 & 9 & 10 & 18 & 6 & 16 & 2 & 15 & 17 & 6 & 16 & 17 & 5 & 30 & 27 & 36 & 29 \\
$\mathrm{Sr}$ & 421 & 284 & 323 & 308 & 313 & 277 & 406 & 309 & 395 & 418 & 415 & 283 & 492 & 453 & 408 & 271 & 254 & 266 & 271 & 250 & 238 & 244 & 249 \\
$\mathrm{Nb}$ & 15 & 13 & 16 & 13 & 20 & 14 & 22 & 21 & 14 & 27 & 19 & 11 & 25 & 22 & 23 & 23 & 17 & 21 & 16 & 9 & 17 & 24 & 14 \\
$\mathrm{Zr}$ & 155 & 152 & 141 & 145 & 142 & 146 & 220 & 198 & 203 & 208 & 158 & 199 & 253 & 270 & 213 & 178 & 190 & 180 & 222 & 193 & 178 & 186 & 176 \\
$\mathrm{Y}$ & 37 & 34 & 31 & 27 & 23 & 31 & 43 & 35 & 33 & 26 & 30 & 37 & 32 & 47 & 34 & 42 & 32 & 41 & 71 & 48 & 37 & 37 & 44 \\
$\mathrm{Ba}$ & 368 & 287 & 337 & 257 & 346 & 336 & 414 & 498 & 402 & 331 & 318 & 369 & 520 & 571 & 497 & 435 & 415 & 450 & 732 & 521 & 416 & 547 & 459 \\
\hline
\end{tabular}

\begin{tabular}{|c|c|c|c|c|c|c|c|c|}
\hline \multirow[b]{2}{*}{$L a$} & \multirow[b]{2}{*}{17,50} & \multirow[b]{2}{*}{16,70} & \multicolumn{6}{|c|}{ Elementos terras raras (ppm) } \\
\hline & & & 28,30 & 19,50 & 22,10 & 29,30 & 33,40 & 21,90 \\
\hline $\mathrm{Ce}$ & 40,80 & 37,50 & 65,80 & 43,60 & 49,80 & 68,80 & 77,30 & 51,90 \\
\hline$N d$ & 20,10 & 19,30 & 33,40 & 22,70 & 26,90 & 36,50 & 40,70 & 25,00 \\
\hline $\mathrm{Sm}$ & 4,80 & 4,70 & 7,40 & 5,30 & 6,30 & 8,20 & 8,90 & 5,90 \\
\hline$E u$ & 1,50 & 1,50 & 2,20 & 1,70 & 1,90 & 2,30 & 2,60 & 1,80 \\
\hline$G d$ & 5,00 & 4,90 & 7,20 & 5,40 & 6,20 & 7,40 & 8,30 & 6,10 \\
\hline Dy & 5,70 & 4,30 & 6,10 & 4,40 & 5,60 & 5,90 & 6,30 & 5,80 \\
\hline$E r$ & 3,90 & 2,70 & 3,30 & 2,60 & 3,10 & 3,00 & 3,30 & 3,40 \\
\hline$Y b$ & 3,40 & 2,40 & 2,90 & 2,10 & 2,80 & 2,50 & 2,70 & 3,10 \\
\hline$L u$ & 0,49 & 0,33 & 0,38 & 0,27 & 0,36 & 0,33 & 0,35 & 0,44 \\
\hline
\end{tabular}




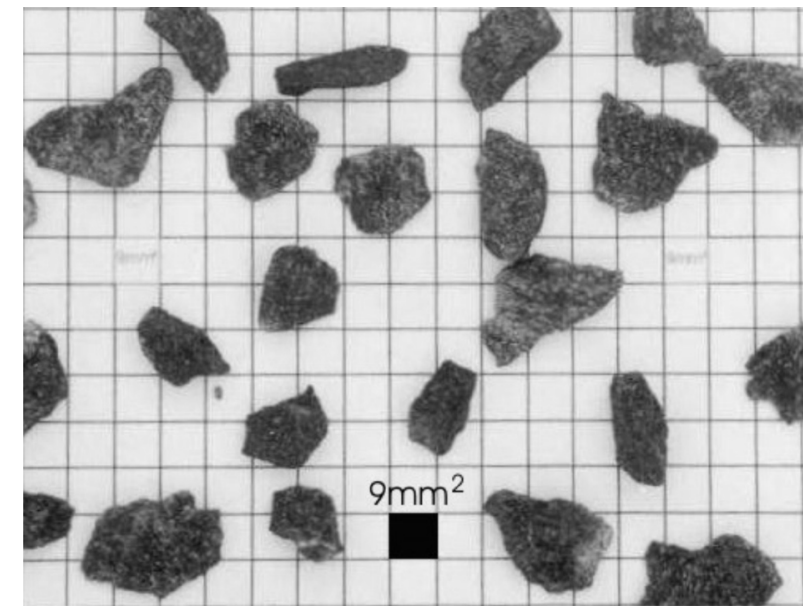

Figura 3 - Fotografia da uma amostra de calha (PMA-164) coletada durante a perfuração do furo de sondagem no intervalo de 162 a $164 \mathrm{~m}$ de profundidade, mostrando basalto afanítico, maciço, de coloração cinza escuro.

sio, minerais opacos (provavelmente magnetita e ilmenita) e olivina. O plagioclásio é o componente mineralógico predominante, alcançando cerca de $50 \%$ do volume da rocha. Ocorre como microfenocristais e na matriz da rocha, com granulação inferior a $0,2 \mathrm{~mm}$. Os microfenocristais são subhedrais, ripiformes, com geminação polissintética, Carlsbad e Carlsbad-Albita. Apresentamse algumas vezes com zoneamento e em outras, com as bordas corroídas pela matriz. Por vezes, os cristais de plagioclásio estão saussuritizados.

Os clinopiroxênios possuem natureza cálcica e subcálcica, constituindo cerca de $45 \%$ do volume das rochas. São na maioria das vezes anhedrais e secundariamente subhedrais. Ocorrem na matriz com hábito granular ou como microfenocristais poiquilíticos.

A olivina está total ou parcialmente alterada para um mineral castanho-avermelhado, provavelmente idingisita. Ocorre na matriz como microfenocristais arredondados envoltos por clinopiroxênios, na maioria das vezes. Os cristais de olivina não chegam a atingir $5 \%$ do volume das rochas.

Os minerais opacos, provavelmente magnetita e ilmenita, chegam a constituir $20 \%$ do volume total das rochas. Ocorrem intersticialmente, na matriz, e como microfenocristais, freqüentemente subhedrais.

$\mathrm{O}$ material vítreo de coloração marrom escuro a preto, isotrópico, ocorre intersticialmente na matriz. Apresenta composição volumétrica variável, chegando a atingir mais de $60 \%$ do volume total das rochas.

Os cristais de plagioclásio juntamente com os clinopiroxênios constituem a trama fundamental das rochas. Os grãos de clinopiroxênio ocorrem intersticialmente e, também, como microfenocristais poiquilíticos, envolvendo plagioclásios e opacos. Os microfenocristais idiomórficos de plagioclásio, por vezes, estão orientados segundo a direção de fluxo da lava, configurando textura pilotaxítica. O plagioclásio ocorre também como cris-

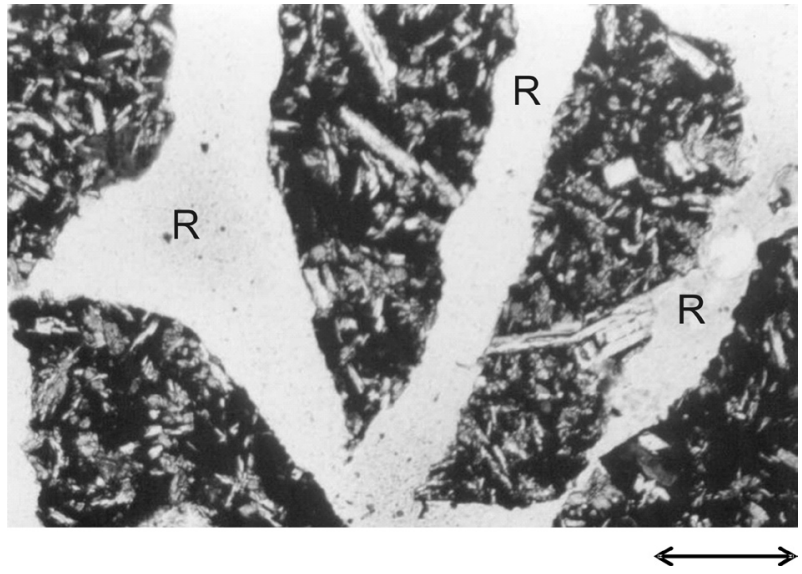

Figura 4 - Fotomicrografia de uma amostra de caIha (PMA 34) do furo de sondagem, constituida por pequenos fragmentos de amostra soldados por resina epóxi (R). A seção mostra microfenocristais ripiformes de plagioclásio e clinopiroxênio, imersos em matriz vitrea abundante. Escala: a seta possui $0,1 \mathrm{~mm}$.

tais tipo "cauda de andorinha", que constituem estruturas típicas de resfriamento rápido. Os cristais de opacos ocorrem intersticialmente na matriz, e como fenocristais subhedrais, poiquilíticos, envolvendo cristais de clinopiroxênio e plagioclásio.

Nas amostras representativas dos topos dos derrames, a matriz é constituída, predominantemente, por material vítreo. São comuns, também, as ocorrências de estruturas vesiculares/amigdaloidais preenchidas por zeólitas.

O reconhecimento de feições características de topo e base dos derrames como a presença de zonas vesiculares e amigdaloidais, brechas e zonas de alteração supergênica, permitiu a identificação de 27 derrames distintos, com espessuras que variam entre 10 e $80 \mathrm{~m}$, conforme mostra a figura 2 .

LITOGEOQUÍMICA Um conjunto de 23 amostras coletadas na região, sendo 15 de subsuperfície (PMA) e outras 8 de superfície $(\mathrm{P})$ foi analisado por fluorescência de raios X para elementos maiores e traços. No primeiro caso, foram utilizadas pastilhas fundidas em borato na proporção de 1:5, e no segundo, pastilhas de pó misturado a $25 \%$ de cera micropulverizada e prensados a $30 \mathrm{~T} . \mathrm{cm}^{-2}$ (Nardy et al. 1997). Determinou-se também a perda de voláteis das amostras (LOI), através do aquecimento das mesmas em forno mufla, a uma temperatura pré-estabilizada de $1000^{\circ} \mathrm{C}$, durante $4 \mathrm{~h}$. Desse conjunto, 8 amostras foram selecionadas para análises de elementos terras raras, pré-concentradas por cromatografia em resinas trocadoras de íons e quantificadas por espectrometria de plasma acoplado indutivamente (ICP-OES) empregando-se nebulização ultrassônica (Malaguti et al. 1998). Os resultados obtidos encontram-se listados na tabela 1 e os erros analíticos envolvidos nas análises podem ser avaliados através da comparação com amostras de referência internacionais 
apresentadas na tabela 2 (seg. Govindaraju, 1989).

O diagrama TAS da figura 5 , mostra que as amostras da região de Araçatuba apresentam, de maneira geral, baixa relação álcalis/sílica e portanto, afinidade subalcalina, de composição básica-intermediária, com concentrações de $\mathrm{SiO}_{2}$ variando entre $48,83 \%$ e $54,38 \%$, ou seja, a sua grande maioria está situada no campo do basalto, deslocado em direção ao andesito basáltico, embora apenas uma das amostras (PMA-710) esteja situada nesse último campo. Além disso, essas rochas apresentam caráter toleítico, com forte enriquecimento de ferro em relação aos álcalis e ao magnésio, conforme se observa no diagrama da figura 6. Esse ca-

Tabela 2 - Comparação entre os dados geoquímicos obtidos pelas técnicas analíticas empregadas neste trabatho com aqueles certificados para três materiais de referência internacionais, segundo Govindaraju (1989). As concentrações de elementos maiores e menores tem como unidade de medida a \%peso e a dos traços, ppm.

\begin{tabular}{|c|c|c|c|c|c|c|}
\hline & \multicolumn{2}{|c|}{ QLO-1 } & \multicolumn{2}{|c|}{ B-R } & \multicolumn{2}{|c|}{ RGM-1 } \\
\hline & obtido & certif. & obtido & certif. & obtido & certif. \\
\hline $\mathrm{SiO}_{2}$ & 66,36 & 66,20 & 39,56 & 39,52 & 73,74 & 74,03 \\
\hline $\mathrm{TiO}_{2}$ & 0,63 & 0,63 & 2,70 & 2,69 & 0,30 & 0,27 \\
\hline $\mathrm{Al}_{2} \mathrm{O}_{3}$ & 16,39 & 16,34 & 10,47 & 10,54 & 13,86 & 13,84 \\
\hline $\mathrm{Fe}_{2} \mathrm{O}_{3}{ }^{*}$ & 4,46 & 4,39 & 13,39 & 13,33 & 1,90 & 1,88 \\
\hline $\mathrm{MnO}$ & 0,10 & 0,09 & 0,206 & 0,207 & 0,04 & 0,04 \\
\hline $\mathrm{MgO}$ & 1,05 & 1,01 & 13,80 & 13,74 & 0,29 & 0,28 \\
\hline $\mathrm{CaO}$ & 3,23 & 3,20 & 14,25 & 14,28 & 1,23 & 1,16 \\
\hline $\mathrm{Na}_{2} \mathrm{O}$ & 4,29 & 4,24 & 3,18 & 3,17 & 4,12 & 4,11 \\
\hline $\mathrm{K}_{2} \mathrm{O}$ & 3,70 & 3,64 & 1,47 & 1,45 & 4,36 & 4,34 \\
\hline $\mathrm{P}_{2} \mathrm{O}_{5}$ & 0,26 & 0,26 & 1,09 & 1,08 & 0,05 & 0,05 \\
\hline Soma & 100,47 & 100,00 & 100,12 & 100,00 & 99,89 & 100,00 \\
\hline $\mathrm{Cu}$ & 30 & 29 & 72 & 72 & 11 & 12 \\
\hline$N i$ & 3 & 5 & 263 & 260 & 3 & 4 \\
\hline$B a$ & 1390 & 1370 & 1063 & 1050 & 796 & 807 \\
\hline$R b$ & 73 & 74 & 45 & 47 & 146 & 149 \\
\hline$S r$ & 332 & 336 & 1335 & 1320 & 104 & 108 \\
\hline $\mathrm{Zr}$ & 192 & 185 & 256 & 260 & 230 & 219 \\
\hline$Y$ & 26 & 24 & 29 & 30 & 24 & 25 \\
\hline $\mathrm{Nb}$ & 11 & 10 & 98 & 98 & 10 & 9 \\
\hline$L a$ & 31 & 27 & & & 28 & 24 \\
\hline $\mathrm{Ce}$ & 50 & 54 & & & 44 & 47 \\
\hline$N d$ & 26 & 26 & & & 20 & 19 \\
\hline$S m$ & 5,3 & 4,9 & & & 4,5 & 4,3 \\
\hline$E u$ & 1,4 & 1,4 & & & 0,80 & 0,66 \\
\hline$G d$ & 4,6 & 4,7 & & & 3,5 & 3,7 \\
\hline$D y$ & 3,7 & 3,8 & & & 3,4 & 4,08 \\
\hline Ho & 0,83 & 0,86 & & & 0,77 & 0,95 \\
\hline$E r$ & 2,3 & 2,3 & & & 2,3 & 2,6 \\
\hline$Y b$ & 2,1 & 2,3 & & & 2,3 & 2,6 \\
\hline$L u$ & 0,30 & 0,37 & & & 0,35 & 0,41 \\
\hline
\end{tabular}

ráter toleítico é também corroborado pelo caráter supersaturado em sílica, caracterizado pela presença de quartzo e hiperstênio normativos.

Os diagramas de Fenner, figura 7, revelam que as amostras estudadas não definem trends específicos, com exceção do $\mathrm{Na}_{2} \mathrm{O}$ e do $\mathrm{P}_{2} \mathrm{O}_{5}$, conforme mostram os coeficientes de correlação de Spearman $\left(\mathrm{SiO}_{2}=0,053\right.$; $\mathrm{Al}_{2} \mathrm{O}_{3}=0,598, \mathrm{Fe}_{2} \mathrm{O}_{3} *=0,039 ; \mathrm{CaO}=0,72 ; \mathrm{Na}_{2} \mathrm{O}=$ 0,$632 ; \mathrm{K}_{2} \mathrm{O}=0,162 ; \mathrm{TiO}_{2}=0,636$ e $\left.\mathrm{P}_{2} \mathrm{O}_{5}=0,73\right)$. Consideradas apenas as amostras provenientes do furo de sondagem, ou das pedreiras, verificam-se agora, tren$d s$ um pouco melhor definidos, para a maioria dos elementos, em especial para o $\mathrm{CaO}, \mathrm{Na}_{2} \mathrm{O}$ e $\mathrm{P}_{2} \mathrm{O}_{5}$. A figura

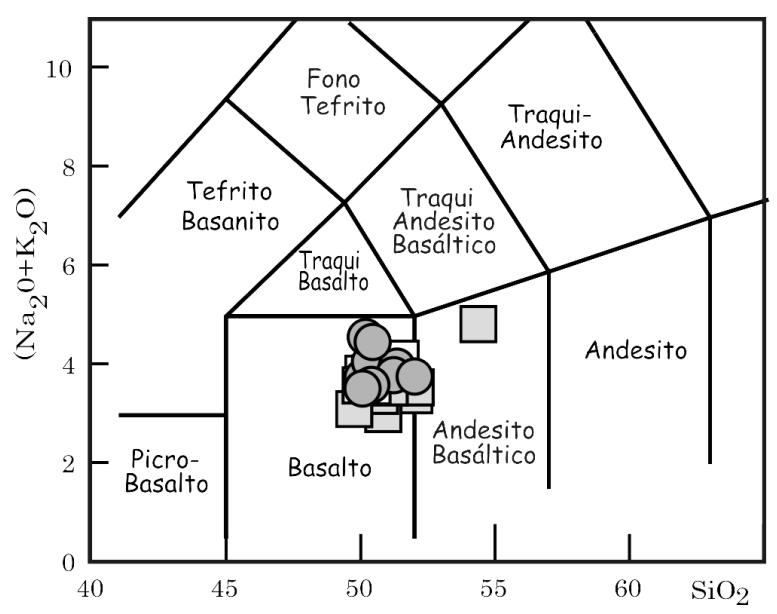

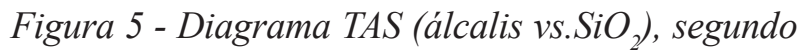
Le Bas et al. (1986). Legenda: círculos- amostras de superficie, quadrados- amostras de subsuperficie.

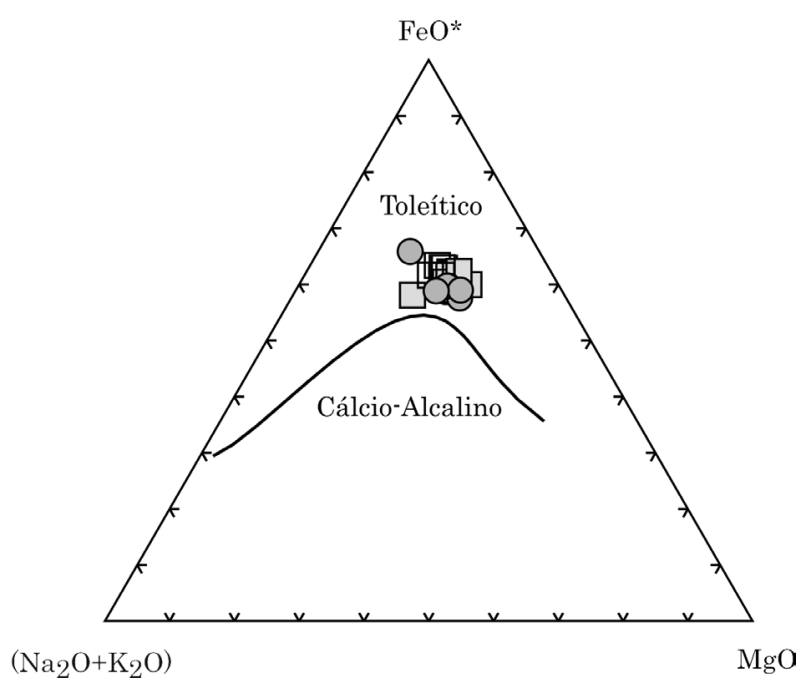

Figura 6 - Diagrama AFM $\left(\mathrm{Na}_{2} \mathrm{O}+\mathrm{K}_{2}\right.$ vs. $\mathrm{FeO} * \mathrm{vs}$. $\mathrm{MgO})$, mostrando o caráter toleítico dos basaltos estudados, segundo Irvine \& Baragar (1971). Legenda: ver figura 5. 

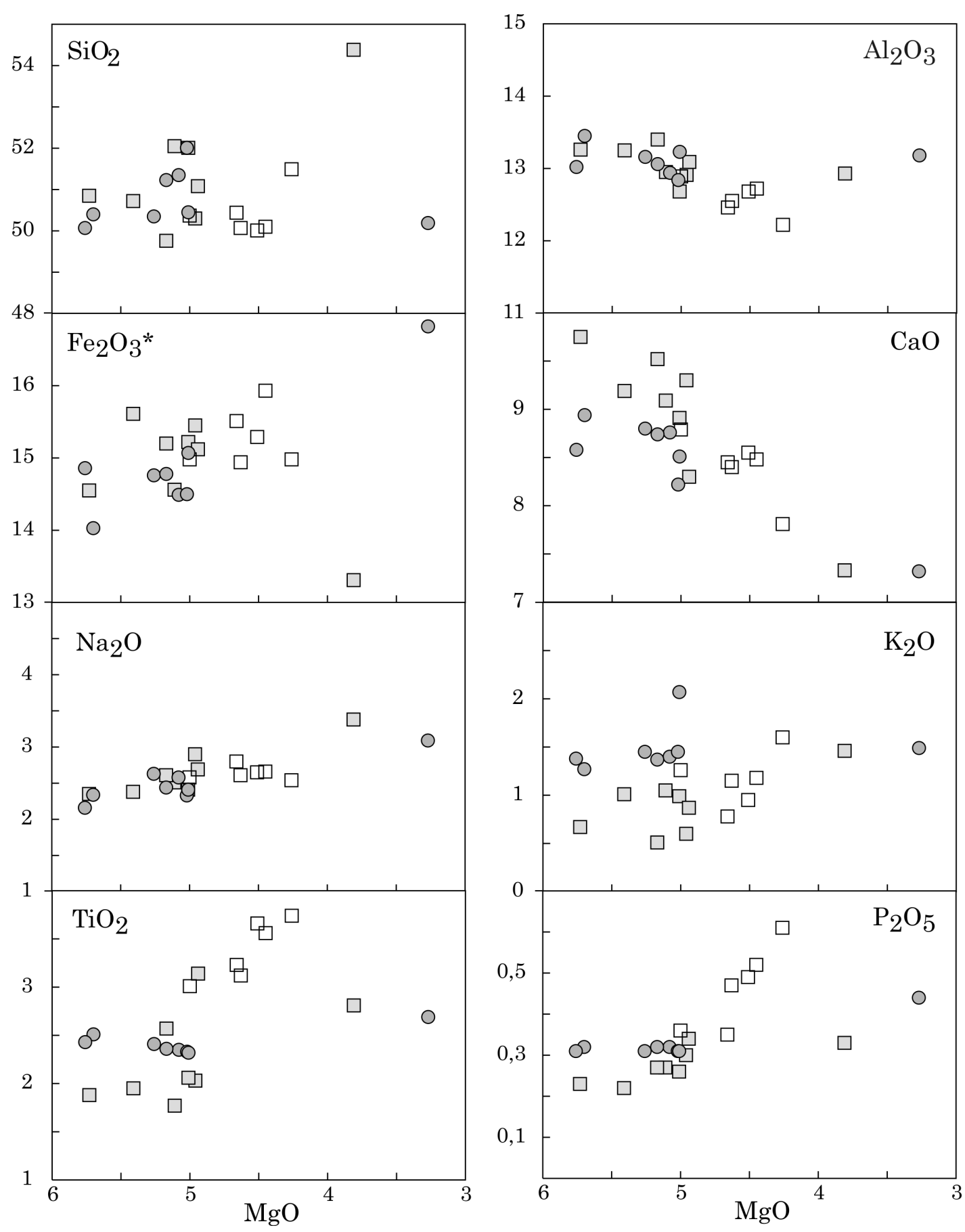

Figura 7 - Diagramas de Fenner para elementos maiores e menores. Legenda: ver figura 5 .

também mostra que as amostras analisadas são todas do tipo alto- $\mathrm{Ti}$, com $\mathrm{TiO}_{2}$ variando entre $1,77 \%$ e $3,74 \%$, sendo que estes valores extremos são observados nas amostras provenientes do furo de sondagem.

O diagrama de elementos incompatíveis normalizados em relação ao manto primordial (Sun \& McDonough, 1989) dos basaltos provenientes do furo de sondagem (PMA-34, PMA-314, PMA454, PMA774 e PMA-904) e a de superfície (P-1), figura 8, mostra a existência de dois grupos distintos, um deles enriquecido em $\mathrm{Nb}(8 \%), \mathrm{K}(9 \%)$, La (11\%), Ce (18\%),
P (8\%), Nd (20\%), Zr (19\%), Sm (17\%), Eu (15\%) e Ti $(15 \%)$ em relação ao outro. Essas diferenças, também são verificadas na avaliação de diagramas de elementos terras raras normalizados em relação ao manto primordial (Sun \& McDonough, 1989), figura 9, onde um deles se mostra muito mais enriquecido em terras raras leves em relação às pesadas do que o outro $(\mathrm{La} /$ Lu iguais, respectivamente, a 9,29 e 5,26). Além disso, ambos os grupos não possuem anomalias negativas de Eu significativas, com $\mathrm{Eu} / \mathrm{Eu}$ *ao redor de 0,90 para o primeiro grupo e 0,93 para o segundo. Isto indica que a 


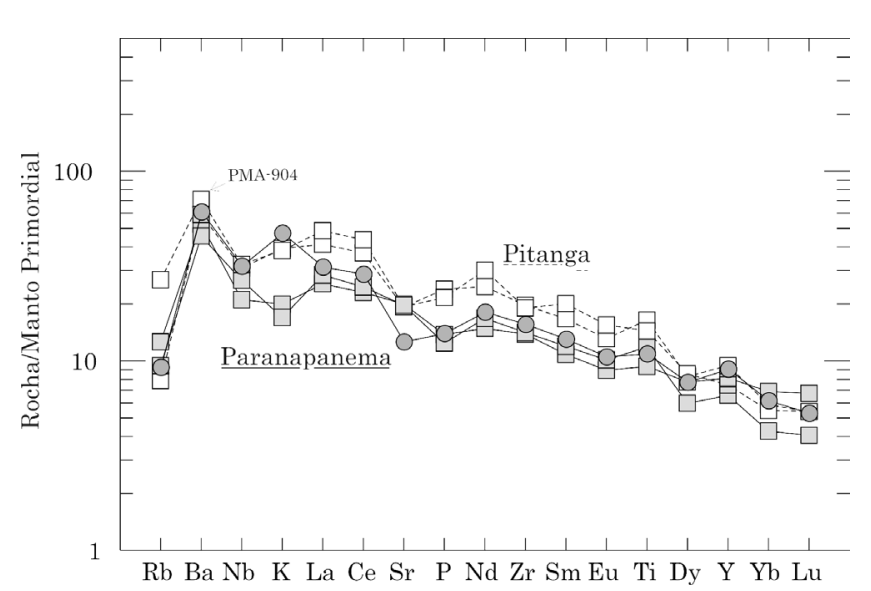

Figura 8 - Diagrama de distribuição de elementos incompativeis normalizados em relação ao manto primordial (Sun \& McDonough 1989). Legenda: ver figura 5.

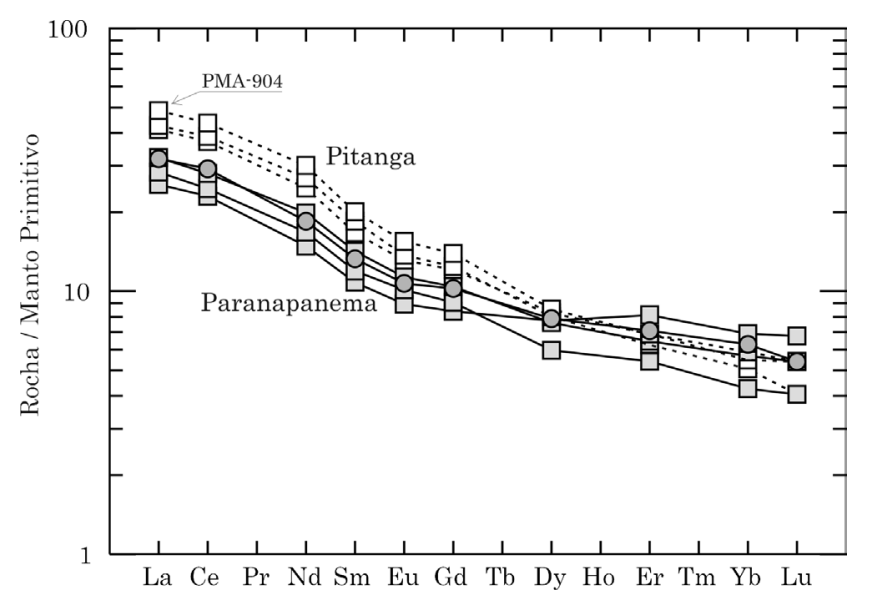

Figura 9 - Diagrama de distribuição de elementos terras raras normalizados em relação ao manto primordial (Sun \& McDonough 1989). Legenda: ver figura 5.

cristalização de plagioclásio não pode ser considerada como responsável pelas diferenças nas concentrações de elementos terras raras, bem como de outros elementos-traço incompatíveis (Fig. 8).

Esses dois grupos podem ser facilmente individualizados através de um diagrama $\mathrm{TiO}_{2} v s \mathrm{Sr}$, com os campos de diferentes magmas-tipo definidos por Peate et al. (1992), figura 10. As amostras enriquecidas em elementos-traço incompatíveis e terras-rara estão concentradas no campo do magma-tipo Pitanga enquanto que as demais, no do Paranapanema. Nesse diagrama, há um pequeno grupo de amostras que está localizado em um campo de sobreposição entre esses dois magmas-tipo (PMA-390, PMA-442, PMA-904). Entretanto, as concentrações de elementos-traço incompatíveis, figura 8 e

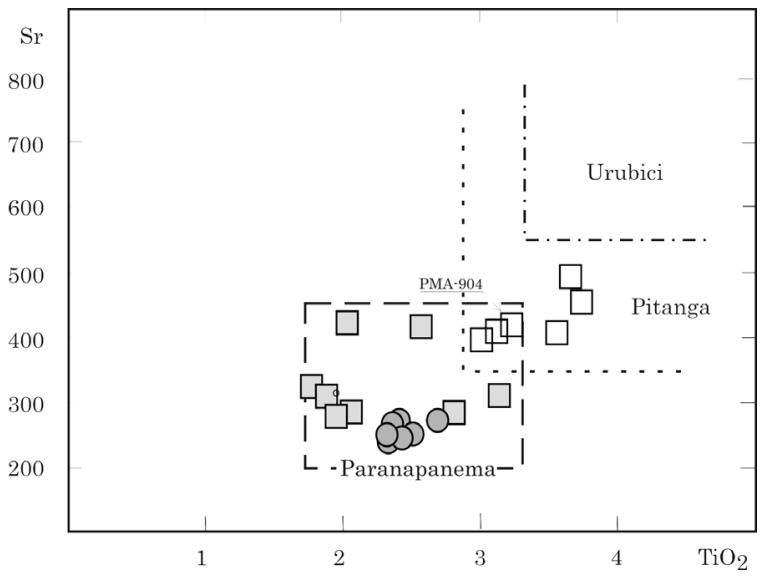

Figura 10 - Diagrama TiO2 vs Sr com os campos dos magmas-tipo altos-em-Ti, segundo Peate et al. (1992). Legenda: ver figura 5.

de elementos terras raras, figura 9, de uma das amostras pertencente a esse grupo (PMA-904), mostra tratar-se de basaltos do tipo Pitanga, muito mais enriquecidos nesses elementos do que aqueles do tipo Paranapanema.

CONSIDERAÇÕES FINAIS Os dados geoquímicos dos basaltos da região de Araçatuba mostraram tratar-se de rochas de caráter toleítico, do tipo alto-Ti, com $\mathrm{TiO}_{2}>1,77 \%$, que podem ser divididas em dois tipos distintos, denominados de Pitanga e Paranapanema (Fig. 10), sendo os primeiros enriquecidos em elementos-traço incompatíveis (Fig. 8) e terras raras (Fig. 9) em relação aos do segundo tipo.

Os basaltos do tipo Paranapanema são encontrados nas pedreiras, no leito do Rio Baguaçu e em subsuperfície, enquanto que os do tipo Pitanga ocorrem exclusivamente em subsuperfície, conforme observado nas amostras de calha obtidas do furo de sondagem PMA, figuras 1 e 2. Nele, os basaltos do tipo Pitanga estão em contato com os arenitos eólicos da Formação Botucatu, a uma profundidade de 980 metros, constituindo uma seqüência de cinco derrames, até a profundidade de 748 metros. A partir de então, inicia-se uma nova seqüência de 10 derrames de basaltos do tipo $\mathrm{Pa}$ ranapanema, até uma profundidade de 396 metros, seguida de três derrames de basaltos do tipo Pitanga, até uma profundidade de 268 metros. Daí até a superfície é observada uma pilha de 9 derrames de basaltos do tipo Paranapanema, conforme mostra a seção colunar da figura 1. Sobreposta a essa seqüência, estão os basaltos encontrados na superfície, em pedreiras e no leito do Ribeirão Baguaçu, todos do tipo Paranapanema.

Esses dados indicam que a seqüência de rochas vulcânicas da região de Araçatuba pode ter sido abastecida por mais de uma câmara magmática, que extravasaram suas lavas em épocas distintas, iniciando com basaltos do tipo Pitanga, em contato com os arenitos da Formação Botucatu, e encerrando a seqüência observada, com aqueles com do tipo Paranapanema. 


\section{Referências}

Bellieni G., Brotzu P., Comin-Chiaramonti P., Ernesto M., Melfi A.J., Pacca I.G., Piccirilo E.M., Stolfa D. 1983. Petrological and Paleomagnetic Data on the Plateau Basalts to Rhyolite sequencies of the Southern Paraná Basin (Brazil). An. Acad. Bras. Ciênc., 55:355-383.

Bellieni G., Comin-Chiaramonti P., Marques L.S., Melfi A.J, Stolfa D. 1984b. Low-pressure evolution of basalt sills from bore-holes in the Paraná Basin, Brazil. TMPM, 33:25-47.

Bellieni G., Comin-Chiaramonti P., Marques L.S., Melfi A.J., Piccirilo E.M., Nardy A.J.R., Roisenberg A. 1984a. High-and-low-Ti flood basalts from the Paraná plateau (Brazil): petrology end geochemical aspects bearing on their mantle origin. Neu. Jahr. Miner. Abh., 150:272306.

Ernesto M., Raposo M.I.B., Marques L.S., Renne P.R., Diogo L.A., de Min A. 1999. Paleomagnetism, geochemistry and ${ }^{40} \mathrm{Ar} /{ }^{39} \mathrm{Ar}$ dating of the North-eastern Paraná magmatic province: tectonic implications. J. Geod., 28:321-340.

Govindaraju K. 1989. 1989 compilation of working values and sample description on 272 geostandards. Geost. News., 13:1-113.

INSTITUTO GEOGRÁFICO E GEOLÓGICO (IGG). 1967. Folha Topográfica de Araçatuba-SF-22-X-C-11-1. 1 mapa colorido, $56 \mathrm{~cm} \times 78 \mathrm{~cm}$, Escala 1:50.000.

Irvine T.N. \& Baragar W.R.A. 1971. A guide to chemical classification of the common volcanic rocks. Can. J. Earth Sci., 8:523-548.

Le Bas M.J., Le Maitre R.W., Streickeisen A., Zanettin B. 1986. A chemical classification of volcanic rocks based on the total alkali silica diagram. J. Petrol., 27:745-750.

Malagutti M.I.A., Bahia Fo O., Moreno M.M.T., Nardy A.J.R. 1998. Determinação de elementos terras raras e ítrio em rochas silicáticas por ICP-AES com separação em resina trocadora de íons. Geoch. Bras., 12:75-80.

Mantovani M.S.M., Marques L.S., Souza M.A., Atalla L., Civeta L., Inonocenti F. 1985. Trace Element and
Strontium Isotope Constrains of the Origin and Evolution of Paraná Coantinental Flood Basalts of Santa Catarina State (Southern Brazil). J. Petrol., 26:187-209.

Marques L.S., Piccirillo E.M., Melfi A.J. Comin-Chiaramonti P., Bellieni G. 1989. Distribuição de Terras Raras e Outros Elementos Traços em Basaltos da Bacia do Paraná (Brasil Meridional). Geoch. Bras., 3(1):33-50.

Marques L.S., Dupré B., Piccirillo E.M. 1999. Mantle source compositions of the Paraná Magmatic Province: Evidence from trace element and $\mathrm{Sr}-\mathrm{Nd}-\mathrm{Pb}$ isotope geochemistry. J. Geod., 28:439-459.

Nardy A.J.R., Enzweiler J., Bahia Fo, O, Oliveira M.A.F., Penereiro M.A.V. 1997. Determinação de elementos maiores e menores em rochas silicáticas por espectrometria de fluorescência de raios-X: Resultados preliminares. In: SBGq, Cong. Bras. de Geoquim., 6, Salvador, BA, Anais, 346-348.

Peate D.W. 1997. The Paraná-Etendeka Province. In: Mahoney J.J \& Coffin M. (eds.) Large Igneous Provinces: Continental, Oceanic, and Planetary Flood Volcanism. American Geophysical Union, Monograph Series, 100:217-245.

Peate D.W., Mantovani M.S.M., Hawkesworth C. 1992. Chemical Stratigraphy of the Paraná Lavas (South America): classification of magma types and their spatial distribution. Bull. of Volcan., 55:119-139.

Sun S. \& McDonough W.F. 1989. Chemical and isotopic systematic of oceanic basalts: implications for mantle composition and processes. In: Saunder A.D. \& Norry A. (eds.) Magmatism in ocean basins. Geol. Soc. Special Publication, 42:313-345.

Manuscrito ID 11549

Submetido em 23 de maio de 2008 Aceito em 20 de setembro de 2008 Sistema eletrônico de submissão 